\title{
Loss-Averse Inventory and Borrowing Decisions with Constraints on Working Capital in Fashion and Textiles Industry
}

\author{
Lijun Ma, ${ }^{1}$ Weili Xue, ${ }^{2}$ Yingxue Zhao, ${ }^{3}$ and Xudong Lin ${ }^{1}$ \\ ${ }^{1}$ Department of Management Science, College of Management, Shenzhen University, Shenzhen 518060, China \\ ${ }^{2}$ School of Economics and Management, Southeast University, Nanjing 210096, China \\ ${ }^{3}$ School of International Trade and Economics, University of International Business and Economics, Beijing 100029, China \\ Correspondence should be addressed to Weili Xue; wlxue1981@gmail.com
}

Received 29 December 2012; Accepted 16 January 2013

Academic Editor: Tsan-Ming Choi

Copyright (C) 2013 Lijun Ma et al. This is an open access article distributed under the Creative Commons Attribution License, which permits unrestricted use, distribution, and reproduction in any medium, provided the original work is properly cited.

\begin{abstract}
Traditional inventory models focus on operational decisions and inventory control. Quite few models consider the financial constraint and decision bias such as loss aversion, which are the reality in today's business environment, especially for the fashion and textiles industry. In this paper we study the inventory control problem for a loss-averse retailer with financial constraint for operations in a periodic review setting in a finite horizon. We characterize the optimal inventory control policies with self-financing or with borrowing as capital-dependent base-stock policies. We demonstrate with numerical examples that the optimal base-stock level is nonincreasing in the accumulated wealth and the loss-aversion indicator.
\end{abstract}

\section{Introduction}

The fashion and textiles industry is characterized by short product lifecycle, high volatility, and low predictability, which cause financial risk to the companies in the industry. This is true especially for those start-up and growing firms in the fashion and textiles industry, who always encounter credit and capital shortage problems. According to the empirical evidence from Ayyagari et al. [1], worldwide small and medium-sized enterprises (SMEs) frequently tend to report financing as a major obstacle compared to large firms. Thus, it is important for those companies to take their financial states into consideration when making operations decisions.

However, although there is an extensive literature on inventory control problems in both deterministic and stochastic environments, few models consider the firms' financial decisions when characterizing the optimal inventory policy. Among them, Kogut and Kulatilaka [2] model the coordination of geographically dispersed subsidiaries as an option dependent upon the real exchange rate; Huchzermeier and Cohen [3] develop a firm valuation model through the exercise of production and supply chain network options. Birge [4] adapts real option pricing theory for incorporating risk into capacity planning by assuming the availability of market hedges. Other models include those of Hadley and Whitin [5] and Rosenblatt [6]. But all the previous models treat the budget fixed for each period (i.e., exogenously determined) and can not be affected by the inventory decisions. Two exceptions are Rosenblatt and Rothblum [7] and Chao et al. [8]. The former study a multiitem inventory system under a single resource capacity and they treat the capacity as a decision variable, while the latter study inventory control problem with cash flow constraint. However, they do not consider the financing decisions which is common in real business environment.

The managers' decision bias, which means that their decisions are not always consistent with optimal decisions under profit-maximizing or cost-minimizing objective, has been recognized by researchers and practitioners. For example, Kahn [9] states that Chrysler held larger inventory than competitors such as GM and Ford before early 1980, which is called stockout-avoidance behaviour (see [10]). One major 
reason why decision bias exists is that a manager may have preferences rather than being risk neutral (see [10]). According to loss-averse theory, people are more averse to losses than they are attracted to the same-sized gains. This is also one kind of risk-averse behaviour, which is well supported in the finance, economics, marketing, and organizational behaviour literature (see [11]). Besides, Schweitzer and Cachon [12] and Wang and Webster [10] introduce loss-aversion preference in the newsvendor model. However, they only focus on the single period problem and never consider the financial constraint, which is important for the SMEs in the fashion and textiles industry and will be addressed in this paper.

In summary, we study the inventory control and financing decision problems for a loss-averse retailer when the retailer is confronted with a financial constraint in this paper. Using a lost-sales model, we first investigate the inventory control policy for a loss-averse retailer with borrowing decisions in a finite horizon model. We find that the optimal inventory policy follows a capital-dependent base-stock policy. Then, we extend the basic model to the self-financing situation and find that the optimal inventory policy also follows a capitaldependent base-stock policy. We also study how the optimal replenishment level changes according to different parameter settings with self-financing.

The rest of this paper is organized as follows. We review the related literature in Section 2. Section 3 presents the lostsales model with the objective of maximizing the utility of the terminal wealth with borrowing and with self-financing. Section 4 presents the comparative statics for the models with self-financing. Section 5 concludes the paper.

\section{Literature Review}

Our research is mainly related to two streams of literature: the inventory models with decision criteria other than risk neutral and the inventory models with financial consideration.

Traditional inventory models consider the risk neutrality, that is, either maximizing the total profit or minimizing the total cost. However, decision makers do have risk preferences other than risk neutrality. Lau [13] analyzes the classical newsvendor model under two different objective functions. In the first objective, the focus is on maximizing the decision maker's expected utility of total profit. The second objective function is the maximization of the probability of achieving a certain level of profit. Eeckhoudt et al. [14] focus on the effects of risk and risk aversion in the newsvendor model when risk is measured by expected utility functions. In particular, they determine comparative-static effects of changes in the various price and cost parameters in the risk aversion setting. Chen and Federgruen [15] analyze the mean-variance tradeoff in the newsvendor models as well as some standard infinite horizon inventory models. particular, in the infinite horizon models, they focus on the mean-variance tradeoff of customer waiting time as well as the mean-variance tradeoff of inventory levels. Choi et al. [16] study a single supplier and retailer supply chain under a returns policy in mean-variance framework. Choi et al. [17] study the channel coordination problem in supply chains with agents having mean-variance objectives. Hafezalkotob et al. [18] study the strategic and tactical design of competing decentralized supply chain networks for markets with uncertain demand in a mean-variance framework. Ma et al. [19] study the channel bargaining problem of the single two-echelon supply chain under the conditional value-at-risk $(C V a R)$. Chen et al. [20] consider a finite horizon inventory decision problem with exponential utility functions. They work out the optimal inventory decision as well as the optimal pricing behavior. Buzacott et al. [21] study a class of commitment-option supply contracts in a mean-variance framework. Recently, Choi and Chiu [22] summarize their research in supply chain management area with the mean-risk framework in a monograph. The previous literature deals with risk-averse behavior rather than loss-averse behavior. For the loss-averse behavior, Wang and Webster [10] study the newsvendor problem under the loss-averse utility function with a zero profit target. Ma [23] extends their work to include a general reference target to study the newsvendor problem. Wang [24] studies the lossaverse newsvendor game and finds the condition for the existence of Nash equilibrium order quantity, as well as the tradeoff between the loss-aversion effect and the demandstealing effect. Shen et al. [25] study the component procurement problem for the loss-averse manufacturer, while the manufacturer is confronted with a single-whole-sale-price contract and a spot purchase opportunity. Ma et al. [26] study the fashion industry quick response problem in a lossaverse framework. However, for those papers that consider loss-averse utility functions, none of them consider capital constraint in the model.

Financial and operational decisions are usually studied separately. The separation can be justified by the seminal work of Modigliani and Miller [27], which proves that a firm's investment and financial decisions can be made separately in a perfect capital market. However, due to the existence of taxes, agency costs, and asymmetric information, the capital market is not perfect in reality (see Harris and Raviv [28] for a general review). Further, many firms' growth is indeed constrained by the limited internal capital and the availability of credit from banks, supply chain partners. In this context, a firm's operational decisions may in fact be closely related to its financial constraints.

Recently, researchers in operations management field have recognized the importance of the interaction between operational and financial decisions and tried to incorporate the financial considerations into operational decisions. For the single period model setting, Gupta and Gerchak [29] model the impact of operational synergies in the valuation of targets in merger/acquisition cases. Zhou and Groenevelt [30] study the problem when supplier offers financial subsidies to a financially constrained retailer in a newsvendor setting. Dada and Hu [31] study a cash-constrained retailer's optimal ordering quantity when a bank, as the Stackelberg leader, tries to maximize profit in a newsvendor setting. Lai et al. [32] discuss the preorder and consignment operations modes for a cash constrained supplier. Yang and Birge [33] analyze the role of trade credit in a "selling to the newsvendor setting" and conclude that trade credit acts as a risk-sharing mechanism to mitigate the operational and financial risks. 
Kouvelis and Zhao [34] compare supplier financing with bank financing and show that bank financing is superior. Jing et al. [35] use a game-theoretical framework to study the financing equilibrium for the capital constrained retailer. For the multiperiod settings, Archibald et al. [36] assume that startup firms are more concerned with the probability of longterm survival. They study a sequential decision model for a firm with uncertain demand, and the inventory decisions are constrained by the current assets. Babich and Sobel [37] coordinate financial decisions and operational decisions to maximize the expected discounted proceeds from an initial public offering (IPO). The recent research by Buzacott and Zhang [38] establishes the link between the financial state of a firm and the credit that the firm owns. They study the asset financing problem under deterministic demand. $\mathrm{Hu}$ and Sobel [39] extend their work to consider the long-term capital structure. They find that the financial decisions and operational decisions can be separated in the limiting case. However, operational decisions and financial decisions do affect each other in other situations. Chao et al. [8] consider a classic dynamic inventory control problem of a self-financing retailer who periodically replenishes its stock from a supplier and sells it to the market. The replenishment decisions are constrained by the cash flow, which is updated periodically following purchase and sales in each period. Hu et al. [40] study the optimal joint decision of inventory, dividend, and debt given that there is possibility of bankruptcy. They show that the coordinated firm should be more highly leveraged than if it were decentralized. Song and Tong [41] develop models to evaluate how payment schemes affect a firm's costs and inventory decision parameters for the EOQ and the basestock models. Luo and Shang [42] study the joint inventory and cash payment decision problem in a two-echelon supply chain under the flexible payment (FP) scheme and the strict payment (SP) scheme. However, these papers do not take the loss-aversion decision bias into consideration.

In this paper, we extend Chao et al.s study [8] by incorporating the retailer's loss-averse behavior and the borrowing decisions. That is, we consider the inventory and financing decisions for a loss-averse retailer who has financial constraint when making decisions. Our goal in this paper is to show (1) the optimal inventory and financing policies for the firm with financial constraint and (2) how the loss-averse behavior of the retailer affects the optimal polices. The joint consideration of operational department and finance department gives this paper a feasible position in real business decision making.

\section{Model Formulation}

Few traditional inventory models take financial constraint of the decision maker into consideration when deriving the optimal ordering policy. However, in practice, operations are always constrained by the decision maker's available cash and borrowing or investing is popular. Thus, the decision maker should make a tradeoff between operating, financing, and investing when making operation decisions. To address such tradeoffs, we consider a loss-averse retailer, whose utility is measured by the loss-averse function, that makes replenishment and financial decisions over a finite horizon $T$ periods with the objective of maximizing the utility of the final wealth at the end of the time horizon. The discount factor is assumed to be 1 for simplicity. Models based on this approach are referred to as the net present value models, which have been employed by Bouakiz and Sobel [43].

We number the first period as period 1, while the last period is period $T$. The demands among successive periods, $D_{t}, 1 \leq t \leq T$, are independent and identically distributed with probability density function $f(\cdot)$ and cumulative distribution function $F(\cdot)$. In each period $t$, with initial on hand capital $S_{t}$ and the inventory level $x_{t}$, the retailer should decide the order-up-to level $y_{t}$ with proper financial decisions, if any. The lead time of each order is zero. Then, demand realized, unsatisfied demand is lost, and excess inventory is taken over to the next period. We assume that there are no holding cost for excess inventory and penalty cost for lost sales. This setting is similar to that employed in Chao et al. [8]. The selling price and the linear ordering cost are assumed to be stationary over the time horizon and are denoted by $p$, $c$, respectively. At the end of the planning horizon, excess inventory can be salvaged at value $v$ per unit.

Now we focus on the investing and borrowing decisions of the retailer in our model. At the investment side, we assume that the surplus capital (after paying the procurement cost) can be invested in a savings account to earn an interest rate $r$ per period with the condition

$$
0 \leq v \leq c<(1+r) c<p
$$

If these conditions are not satisfied, the firm would always prefer to invest all his capital in the banking account without ordering. While at the financing side, we will consider two cases: in the first case, the retailer can borrow from an outsider cash provider with no limit for an exogenously determined interest rate; in the second case, the retailer is selffinanced.

Before we further analyze the different cases, we first introduce the loss-averse utility function this paper employs to measure the retailer's utility. This utility function is first introduced by Kahneman and Tversky [44], who argue with experiment that the decision maker is risk averse about gain and risk seeking about loss, and given the same variation in the absolute value, there is a greater impact of losses than of gains. The utility function can be written as follows:

$$
u(w)=w-\beta(\alpha-w)^{+}
$$

where $\beta>0 . w$ is the wealth level. $\beta$ is the coefficient of penalty for the failure to reach the targeted profit level. $\beta$ can be thought of as a loss-averse indicator. The larger the $\beta$ is, the more loss averse the decision maker is. $\alpha \in \mathbb{R}$ is the reference wealth required by the decision maker.

Lemma 1. The utility function $u(w)$ is an increasing concave function.

Proof. The proof is straightforward. 
3.1. Decision Analysis with Borrowing. In this case, the retailer can borrow from an outsider cash provider to finance his inventory decision during the planning horizon. We assume that there is no limit for borrowing for the sake of simplicity. Denote the borrowing interest rate by $b$ per period. Assume $b>r$ and $p>(1+b) c$; otherwise there are arbitrage opportunities in the model. This assumption also implies that the retailer should always use up all the capital on hand before borrowing from the outside cash providers, and the retailer should always pay the debt whenever he has surplus capital. Moreover, once the order policy is determined, the financial decisions are also determined. That is, at period $t$, with inventory level $x_{t}$ and capital level $S_{t}$, if the inventory policy is to order up to $y_{t}$, then the amount he needs to borrow is $c\left(y_{t}-x_{t}\right)-S_{t}$ when $c\left(y_{t}-x_{t}\right) \geq S_{t}$ and that he needs to deposit is $S_{t}-c\left(y_{t}-x_{t}\right)$ when $S_{t} \geq c\left(y_{t}-x_{t}\right)$. Then, the state transition equation between two successive periods is

$$
\begin{aligned}
S_{t+1}= & (1+r)\left(S_{t}-c\left(y_{t}-x_{t}\right)\right)^{+} \\
& +p \min \left\{y_{t}, D_{t}\right\}-(1+b)\left(c\left(y_{t}-x_{t}\right)-S_{t}\right)^{+},
\end{aligned}
$$

and $x_{t+1}=\left(y_{t}-D_{t}\right)^{+}$; here $(\cdot)^{+}=\max \{\cdot, 0\}$. We will drop the index $t$ for the sake of simplicity in the following presentation.

Therefore, the decision problem is to choose the optimal $\left(y_{1}, y_{2}, \ldots, y_{T}\right)$ to maximize the expected utility at the end of the planning horizon. Specifically, given the initial inventory level $x_{1}$ and initial capital level $S_{1}$, the decision problem is

$$
\max _{y_{1}, y_{2}, \ldots, y_{T}} \mathrm{E} u\left(S_{T+1}\right)
$$

where $u(w)=w-\beta(\alpha-w)^{+}$.

Denote $\bar{V}_{t}(x, S)$ the maximum expected terminal wealth given the inventory level $x$ and capital level $S$ at the beginning of period $t$. Then, the optimality equation is

$$
\bar{V}_{t}(x, S)=\max _{x \leq y} \mathrm{E}\left[\bar{V}_{t+1}\left(\left(y-D_{t}\right)^{+}, S_{t+1}\right)\right],
$$

with a boundary condition

$$
\bar{V}_{T+1}(x, S)=u(S+v x)=S+v x-\beta(\alpha-S-v x)^{+},
$$

and state transition equation (3).

Lemma 2. For any period $t$ and fixed inventory level $x$, $\bar{V}_{t}(x, S)$ is increasing in $S$ and $x$.

Proof. The result can be proved by induction. First, note that at period $T+1, \bar{V}_{T+1}(x, S)=u(S+v x)$ is obviously increasing in $S$ and $x$, as the utility function $u(w)$ is an increasing function with respect to $w$. Then, assuming for fixed inventory level $x$ and period $t+1, \bar{V}_{t+1}(x, S)$ is increasing in $S$ and $x$, we need to prove that this holds for period $t$, in which

$$
\begin{aligned}
\bar{V}_{t}(x, S) & \\
=\max _{x \leq y} \mathrm{E}\left[\bar{V}_{t+1}\right. & \left(\left(y-D_{t}\right)^{+},(1+r)(S-c(y-x))^{+}\right. \\
+ & p \min \left\{y, D_{t}\right\} \\
& \left.\left.-(1+b)(c(y-x)-S)^{+}\right)\right] .
\end{aligned}
$$

Thus, $\bar{V}_{t}(x, S)$ increases in $S$ as $\bar{V}_{t+1}\left(x_{t+1}, S_{t+1}\right)$ is increasing in the second component and $S_{t+1}$ is increasing in $S$. For the monotone property of $\bar{V}_{t}(x, S)$ on $x$, as we will analyze in the following part, the optimal $y$ for the right hand of (7) is one of the following values: $x, S / c+x$ or some values satisfying the first order condition of $\bar{V}_{t+1}\left(x_{t+1}, S_{t+1}\right)$. Thus, it is straightforward to show that as $\bar{V}_{t+1}\left(x_{t+1}, S_{t+1}\right)$ is increasing in both components, $S_{t+1}$ is increasing in $S$.

The monotone property of the value function with the initial cash flow is intuitive. On one hand, the more initial capital the firm has, the better it is for the firm's terminal wealth, which leads to the better firm's terminal utility. On the other hand, the more initial capital the firm has, it provides the firm more flexibility for inventory replenishment, which makes the firm earn at least no less. However, it seems surprising to see that the more the initial inventory is, the better the retailer is. The reason lies in the assumption that there is no holding cost.

To derive the joint concave property of the value function $\bar{V}_{t}(x, S)$, the following lemma is required.

Lemma 3. For any period $t, \bar{V}_{t}(A-z, B+p z)$ is increasing in $z$ for fixed $A$ and $B$.

Proof. Note the following relationship:

$$
\begin{aligned}
\bar{V}_{t}(A-z, B+p z) & \\
=\max _{A-z \leq y} \mathrm{E}[ & \bar{V}_{t+1}\left(\left(y-D_{t}\right)^{+}, p \min \left\{y, D_{t}\right\}\right. \\
+ & (1+r)(c A+B+(p-c) z-c y)^{+} \\
& \left.\left.-(1+b)(c y-(c A+B+(p-c) z))^{+}\right)\right] .
\end{aligned}
$$

It follows from Lemma 2 that the function being maximized previously is increasing in $z$.

Lemma 3 is essential in proving the jointly concave property of the value function. It says that it is better to keep capital than to have inventory at the beginning of every period. This is very intuitive. As capital is more flexible at the beginning of every period, the firm can always convert it into inventory. However, the reverse is not true. In addition, if inventory is more than necessary, inventory should be reduced and cash is saved to earn interest. 
Theorem 4. For any period $t, \bar{V}_{t}(x, S)$ is jointly concave in $x$ and $S$.

Proof. The theorem can be proved by backward induction. Clearly, $\bar{V}_{T+1}(x, S)=u(S+v x)$ is jointly concave in $(x, S)$ as $u(w)=w-\beta(\alpha-w)^{+}$is concave in $w$ from Lemma 1 . Assuming that $\bar{V}_{t+1}(x, S)$ is jointly concave in $(x, S)$, we need to prove the property holding for $\bar{V}_{t}(x, S)$.

To prove that $\bar{V}_{t}(x, S)$ is jointly concave in $(x, S)$, we first prove that $\bar{V}_{t+1}\left(\left(y-D_{t}\right)^{+}, p \min \left\{y, D_{t}\right\}+(1+r)(S-c(y-\right.$ $\left.x))^{+}-(1+b)(c(y-x)-S)^{+}\right)$is jointly concave in $(y, x, S)$. For any $\left(y_{1}, x_{1}, S_{1}\right)$ and $\left(y_{2}, x_{2}, S_{2}\right)$ and $0 \leq \lambda \leq 1$, note that $\left(y-D_{t}\right)^{+}=y-\min \left(y, D_{t}\right)$; denote

$$
\begin{gathered}
\bar{y}=\lambda y_{1}+(1-\lambda) y_{2}, \\
\widetilde{y}=\min \left\{\lambda y_{1}+(1-\lambda) y_{2}, D_{t}\right\}, \\
\widehat{y}=\lambda \min \left\{y_{1}, D_{t}\right\}+(1-\lambda) \min \left\{y_{2}, D_{t}\right\} .
\end{gathered}
$$

We have $\tilde{y} \geq \hat{y}$ as the function $\min \left\{y, d_{t}\right\}$ is concave in $y$ for any demand realization $d_{t}$. Note also that the function $g(z)=(1+r) z^{+}-(1+b)(-z)^{+}$is concave in $z$. Now, we have

$$
\begin{aligned}
& \bar{V}_{t+1}\left(\left(\lambda y_{1}+(1-\lambda) y_{2}-D_{t}\right)^{+}\right. \\
& p \min \left\{\lambda y_{1}+(1-\lambda) y_{2}, D_{t}\right\} \\
& +(1+r)\left(\lambda S_{1}+(1-\lambda) S_{2}\right. \\
& \left.-c\left(\lambda y_{1}+(1-\lambda) y_{2}-\lambda x_{1}-(1-\lambda) x_{2}\right)\right)^{+} \\
& -(1+b)\left(-\lambda S_{1}-(1-\lambda) S_{2}\right. \\
& \left.\left.+c\left(\lambda y_{1}+(1-\lambda) y_{2}-\lambda x_{1}-(1-\lambda) x_{2}\right)\right)^{+}\right) \\
& \geq \bar{V}_{t+1}\left(\bar{y}-\tilde{y}, p \tilde{y}+(1+r)\left(\lambda\left(S_{1}-c\left(y_{1}-x_{1}\right)\right)^{+}\right.\right. \\
& \left.+(1-\lambda)\left(S_{2}-c\left(y_{2}-x_{2}\right)\right)^{+}\right) \\
& -(1+b)\left(\lambda\left(c\left(y_{1}-x_{1}\right)-S_{1}\right)^{+}\right. \\
& \left.\left.+(1-\lambda)\left(c\left(y_{2}-x_{2}\right)-S_{2}\right)^{+}\right)\right) \\
& \geq \bar{V}_{t+1}\left(\bar{y}-\widehat{y}, p \widehat{y}+(1+r)\left(\lambda\left(S_{1}-c\left(y_{1}-x_{1}\right)\right)^{+}\right.\right. \\
& \left.+(1-\lambda)\left(S_{2}-c\left(y_{2}-x_{2}\right)\right)^{+}\right) \\
& -(1+b)\left(\lambda\left(c\left(y_{1}-x_{1}\right)-S_{1}\right)^{+}\right. \\
& \left.\left.+(1-\lambda)\left(c\left(y_{2}-x_{2}\right)-S_{2}\right)^{+}\right)\right), \\
& =\bar{V}_{t+1}\left(\lambda\left(y_{1}-D_{t}\right)^{+}+(1-\lambda)\left(y_{2}-D_{t}\right)^{+}\right. \text {, } \\
& \lambda p \min \left\{y_{1}, D_{t}\right\}+(1-\lambda) p \min \left\{y_{2}, D_{t}\right\}
\end{aligned}
$$

$$
\begin{gathered}
+(1+r)\left(\lambda\left(S_{1}-c\left(y_{1}-x_{1}\right)\right)^{+}\right. \\
\left.+(1-\lambda)\left(S_{2}-c\left(y_{2}-x_{2}\right)\right)^{+}\right) \\
-(1+b)\left(\lambda\left(c\left(y_{1}-x_{1}\right)-S_{1}\right)^{+}\right. \\
\left.\left.+(1-\lambda)\left(c\left(y_{2}-x_{2}\right)-S_{2}\right)^{+}\right)\right), \\
\geq \lambda \bar{V}_{t+1}\left(\left(y_{1}-D_{t}\right)^{+}, p \min \left\{y_{1}, D_{t}\right\}\right. \\
+(1+r)\left(S_{1}-c\left(y_{1}-x_{1}\right)\right)^{+} \\
\left.-(1+b)\left(c\left(y_{1}-x_{1}\right)-S_{1}\right)^{+}\right) \\
+(1-\lambda) \bar{V}_{t+1}\left(\left(y_{2}-D_{t}\right)^{+}, p \min \left\{y_{2}, D_{t}\right\}\right. \\
+(1+r)\left(S_{2}-c\left(y_{2}-x_{2}\right)\right)^{+} \\
\left.-(1+b)\left(c\left(y_{2}-x_{2}\right)-S_{2}\right)^{+}\right),
\end{gathered}
$$

where the first inequality follows from the concavity of $g(z)$ and Lemma 2, the second equality follows from Lemma 3, and the third inequality follows from the concavity of $\bar{V}_{t+1}(x, S)$ on $(x, S)$. Thus, $\bar{V}_{t+1}\left(\left(y-D_{t}\right)^{+}, p \min \left\{y, D_{t}\right\}+(1+\right.$ $r)(S-c(y-x)))$ is jointly concave in $(y, x, S)$ and so are its expectations. Finally, since the feasible range

$$
\mathscr{C}=\{(x, y): x \geq 0, x \leq y\}
$$

is a convex set, applying Proposition B-4 of Heyman and Sobel [45], we conclude that $V_{t}(x, \mathrm{~S})$ is jointly concave in $(x, S)$.

This result establishes the concavity property of the value function, which is useful to further characterize the existence and uniqueness of the optimal policy. However, before that, we should first define the following two functions:

$$
\begin{gathered}
H_{t}(y)=\mathrm{E}\left[\overline { V } _ { t + 1 } \left(\left(y-D_{t}\right)^{+},(1+r)(S-c(y-x))\right.\right. \\
\left.\left.+p \min \left\{y, D_{t}\right\}\right)\right], \\
G_{t}(y)=\mathrm{E}\left[\overline { V } _ { t + 1 } \left(\left(y-D_{t}\right)^{+},(1+b)(S-c(y-x))\right.\right. \\
\left.\left.+p \min \left\{y, D_{t}\right\}\right)\right] .
\end{gathered}
$$

Let $R=S+c x$. Similar to the previous analysis, we can show the concavity of $H_{t}(y)$ and $G_{t}(y)$ and denote their optimal solutions by $y_{t}^{r}(R)$ and $y_{t}^{b}(R)$, respectively.

Then, from Lemma 2 and the assumption that $b>r$, we have $H_{t}(y) \geq G_{t}(y)$ when $S \leq c(y-x)$, while $H_{t}(y) \leq G_{t}(y)$ when $S>c(y-x)$. Thus, we have

$$
\bar{V}_{t}(x, S)=\max _{y \geq x} \min \left\{H_{t}(y), G_{t}(y)\right\} .
$$

Furthermore, we can partially characterize the relationship between $y_{t}^{r}(R)$ and $y_{t}^{b}(R)$ as follows, whose proof is straightforward by contradiction. 
Lemma 5. For any period $t$, one has (2). If $y_{t}^{b}(R) \geq R / c$, then $y_{t}^{r}(R) \geq R / c(3)$. If $y_{t}^{r}(R) \leq R / c$, then, $y_{t}^{b}(R) \leq R / c$.

This lemma implies that it is not possible that $y_{t}^{b}(R)>$ $R / c>y_{t}^{r}(R)$. Moreover, when $y_{t}^{b}(R) \geq R / c, G_{t}(y)$, and $H_{t}(y)$ are increasing for $y \leq R / c$ and the optimal order-up-to level is the optimal solution to $G_{t}(y)$, that is, $y_{t}^{b}(R)$; when $y_{t}^{r}(R) \leq$ $R / c, H_{t}(y)$, and $G_{t}(y)$ are decreasing for $y \geq R / c$, and the optimal order-up-to level is the optimal solution to $H_{t}(\mathrm{y})$, that is, $y_{t}^{r}(R)$; when $y_{t}^{r}(R)>R / c>y_{t}^{b}(R), H_{t}(y)$ is increasing for $y \leq R / c$ and $G_{t}(y)$ is decreasing for $y \geq R / c$, the optimal order-up-to level is $R / c$. We summarize these results by the following theorem.

Theorem 6. When the state is $(x, S)$ at the beginning of period $t$, the optimal policy is to order up to $\bar{y}_{t}^{*}(R)$ whenever $x<$ $\bar{y}_{t}^{*}(R)$, in which

$$
\bar{y}_{t}^{*}(R)= \begin{cases}y_{t}^{b}(R), & \text { if } y_{t}^{b}(R) \geq \frac{R}{c}, \\ \frac{R}{c}, & \text { if } y_{t}^{r}(R)>\frac{R}{c}>y_{t}^{b}(R), \\ y_{t}^{r}(R), & \text { if } y_{t}^{r}(R) \leq \frac{R}{c} .\end{cases}
$$

3.2. Decision Analysis without Borrowing. In this case, the ordering decision satisfies the cash-flow constraint $c\left(y_{t}-\right.$ $\left.x_{t}\right) \leq S_{t}$. The remaining capital in period $t, S_{t}-c\left(y_{t}-x_{t}\right)$, is deposited in the savings account to generate an interest of $r\left(S_{t}-c\left(y_{t}-x_{t}\right)\right)$. The revenue from sales in period $t$ is $p \min \left(y_{t}, D_{t}\right)$. Hence, the total capital level at the end of period $t$ after clearing and settlement are finished, which is also the capital level at the beginning of period $t+1$, is

$$
\begin{array}{r}
S_{t+1}=p \min \left\{y_{t}, D_{t}\right\}+(1+r)\left(S_{t}-c\left(y_{t}-x_{t}\right)\right), \\
t=1,2, \ldots, T .
\end{array}
$$

Then, the decision problem is the same as (4) subject to additional constraints:

$$
0 \leq y_{t}-x_{t} \leq \frac{S_{t}}{c}, \quad t=1,2, \ldots, N
$$

Denote $V_{t}(x, S)$ the maximum expected terminal wealth given the inventory level $x$ and capital level $S$ at the beginning of period $t$. Then, the optimality equation is

$$
\begin{aligned}
V_{t}(x, S)=\max _{x \leq y \leq x+S / c} \mathrm{E}\left[V_{t+1}(\right. & \left(y-D_{t}\right)^{+}, p \min \left\{y, D_{t}\right\} \\
& +(1+r)(S-c(y-x)))],
\end{aligned}
$$

with a boundary condition:

$$
V_{T+1}(x, S)=u(S+v x)=S+v x-\beta(\alpha-S-v x)^{+} .
$$

The tradeoff in the dynamic programming equation mentioned previously is between ordering inventory and putting cash in savings account. When inventory is ordered, the retailer runs the risk of not selling the inventory and therefore loses the opportunity of earning an interest. Note that the problem in the final period is effectively a newsvendor problem with order quantity limit under loss-averse utility function. To derive the optimal inventory control policy, preliminary results are needed. Similar to the analysis when there are borrowing opportunities, we neglect the proofs here.

Theorem 7. For any period t, the following results hold:

(1) $V_{t}(x, S)$ is increasing in $x$ and $S$;

(2) $V_{t}(A-z, B+p z)$ is increasing in $z$ for fixed $A$ and $B$;

(3) $V_{t}(x, S)$ is jointly concave in $x$ and $S$.

Now, we can come up with the following policy conclusion.

Theorem 8. When the state is $(x, S)$ at the beginning of period $t$, a capital-dependent base-stock inventory policy $y_{t}^{*}(R)$ is optimal. More specifically,

(i) if $x \leq y_{t}^{*}(R)-S / c$, it is optimal to order up to $R / c$;

(ii) if $y_{t}^{*}(R)-S / c<x<y_{t}^{*}(R)$, then it is optimal to order up to $y_{t}^{*}(R)$;

(iii) if $x \geq y_{t}^{*}(R)$, then it is optimal not to order.

Refer to $y_{t}^{*}(R)$ as the optimal order-up-to level for period $t$. As we can see from the previous theorem, the optimal achieved inventory level is $\min \left\{y_{t}^{*}(R), R / c\right\}$, which is the minimization of the unconstrained optimal order-up-to level and the financially constrained capacity. Let

$$
\hat{y}_{t}^{*}(R)=\min \left\{y_{t}^{*}(R), \frac{R}{c}\right\}
$$

and refer to $\widehat{y}_{t}^{*}(R)$ as the optimal replenishment level of period $t$. Therefore, at the beginning of period $t$, if $x \leq \widehat{y}_{t}^{*}(R)$, it is optimal to order up to $\widehat{y}_{t}^{*}(R)$; otherwise, do not order.

\section{Comparative Statics}

We present numerical examples to demonstrate the optimal inventory policy and its dependency on wealth level $R$, the loss-averse coefficient $\beta$, the target profit level $\alpha$, the salvage value $v$, and the interest rate $r$. The model parameters in all these numerical examples are $p=1.3$ and $c=1$. In Figure 1, the interest rate is set at $r=0.1$ and the target profit level is set at $\alpha=18$. The demand is assumed to be uniform distribution over $[0,40]$. Assume there are totally $T=3$ periods. Because of the complexity of the problem, the numerical results are for period 2. We constrain our study for the self-financing model.

Figure 1 demonstrates how the optimal inventory policy depends on the wealth level $R$ with different loss-averse penalty coefficient $\beta$. As we can see, for given $\beta$, the minimum of the line and the line $R / c$ is the constrained optimal orderup-to level $\hat{y}_{2}^{*}(R)$. For given $\beta$, it is interesting to note that the optimal order-up-to level $y_{2}^{*}(R)$ is complicated and is not even monotone in $R$ on the range $R / c \leq y_{2}^{*}(R)$. However, 


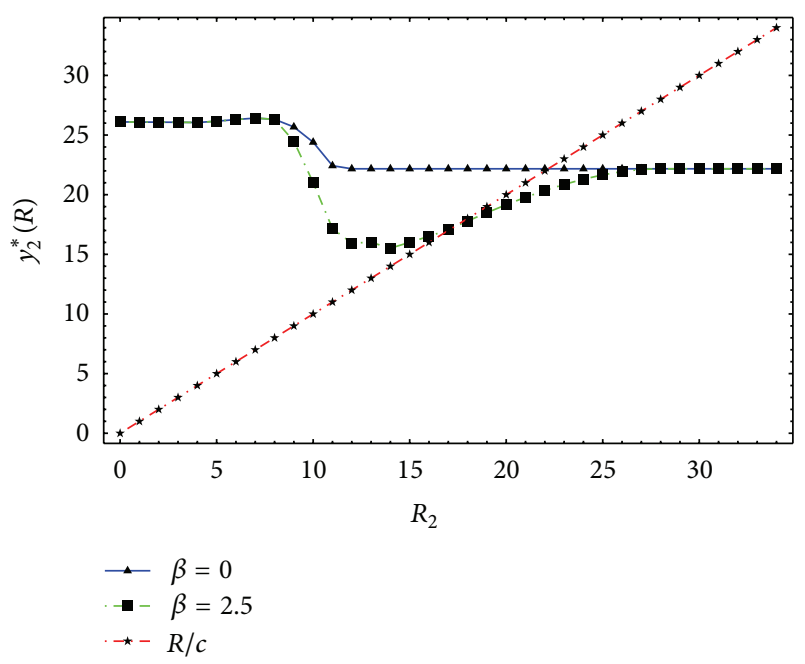

FIGURE 1: Optimal base-stock policy given target profit level.

the optimal constrained replenishment level $\hat{y}_{2}^{*}(R)$ is always extremely simple, which is an increasing function of wealth $R$ when $\beta=0$ and $\beta=2.5$. Given the initial wealth $R$, as $\beta$ increases, the decision maker becomes more loss averse and thus the optimal order-up-to level decreases; this is consistent with the research results applying this loss-averse utility function (see $[10,23])$.

Figure 2 demonstrates how the optimal inventory policy depends on the wealth level $R$ with different target profit level $\alpha$, when the penalty coefficient $\beta$ is set at $\beta=2.5$. As we can see, for given $\alpha$, the minimum of the line and the line $R / c$ is the constrained optimal order-up-to level $\hat{y}_{2}^{*}(R)$. For given $\alpha$, it is interesting to note that the optimal order-upto level $y_{2}^{*}(R)$ is complicated and is not even monotone in $R$ on the range $R / c \leq y_{2}^{*}(R)$. However, the optimal constrained replenishment level $\hat{y}_{2}^{*}(R)$ is always extremely simple, which is an increasing function of wealth $R$ when $\alpha=0,18$, 50 . Given the initial wealth $R$, as $\alpha$ increases from 0 to 50 , the optimal order-up-to level first decreases and then increases until it becomes constant; this is consistent with the research results applying this loss-averse utility function for a multiperiod setting (see [23]).

Figure 3 demonstrates how the optimal inventory policy depends on the salvage value at the end of the time horizon with different initial wealth level $R$. As we can see, for given $R_{2}$, the unconstrained optimal order-up-to level $y_{2}^{*}(R)$ is increasing as the salvage value increases. This is natural as salvage value increases, the risk of overstocking decreases; thus the optimal order-up-to level increases. Moreover, for given salvage value, as the initial wealth $R_{2}$ increases, the decision maker also prefers to order more.

Figure 4 demonstrates how the optimal inventory policy depends on the interest rate at the end of the time horizon with different initial wealth level $R$. As we can see, for given $R_{2}$, the unconstrained optimal order-up-to level $y_{2}^{*}(R)$ is decreasing as the interest rate increases. This is natural since as interest rate increases, the risk of understocking decreases; thus the optimal order-up-to level decreases. Moreover, for

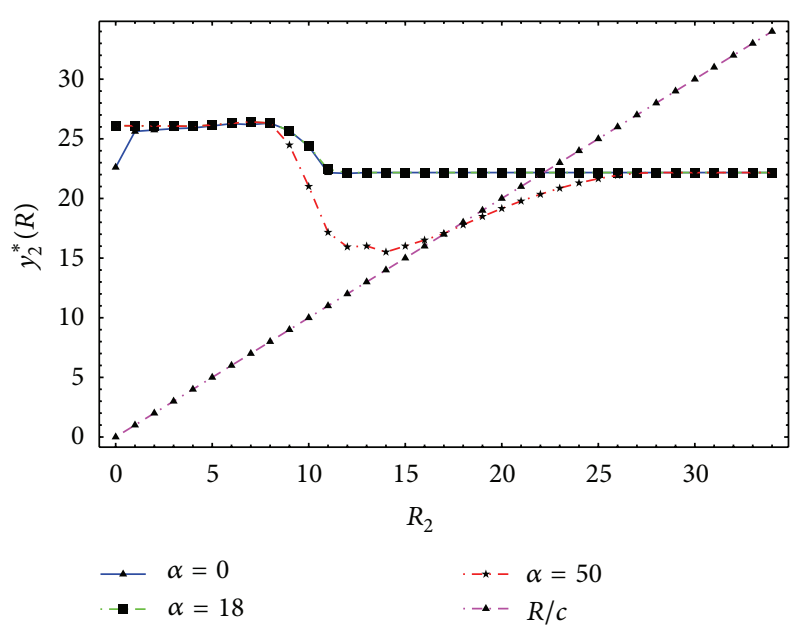

FIGURE 2: Optimal base-stock policy given penalty coefficient.

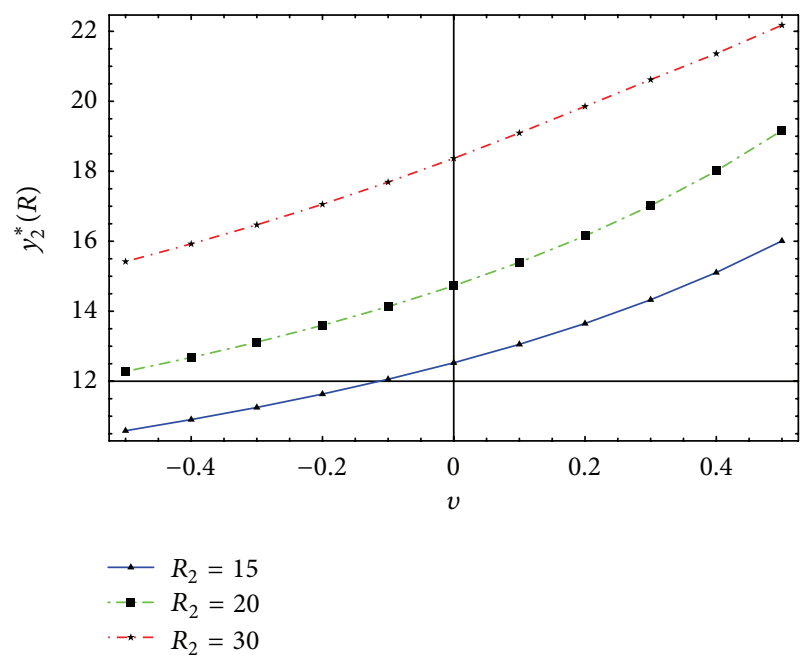

FIGURE 3: The optimal control strategy $y_{2}^{*}(R)$ on $v$.

given interest rate, as the initial wealth $R_{2}$ increases, the decision maker also prefers to order more.

\section{Conclusion}

Traditional inventory models usually do not take the financial constraints into consideration. Yet, in practice companies are usually constrained by the cash available for operations. This is especially true during the global financial crisis of 2008. According to the survey of 1050 Chief Financial Officers (CFOs) in the USA, Europe, and Asia, Campello et al. [46] indicate that the financially constrained firms planned deeper cuts in spending and relied heavily on lines of credit during the global financial crisis of 2008. It is therefore important to consider the financial constraints when dealing with the operations decisions such as inventory replenishment.

On the other hand, traditional inventory models usually assume risk neutral objective. Yet, experiments and real business practice have already demonstrated that there exists 


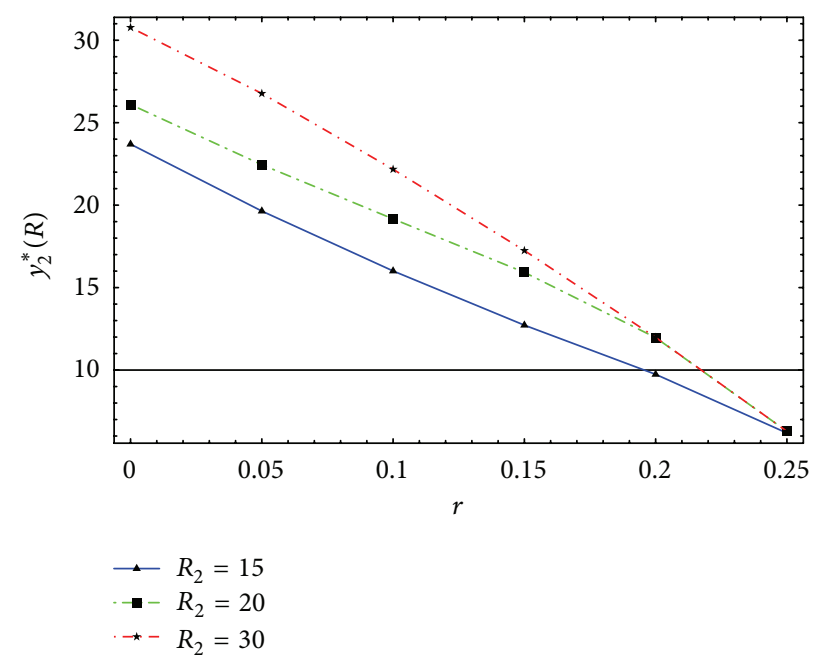

FIGURE 4: The optimal control strategy $y_{2}^{*}(R)$ on $r$.

decision bias. To explain the decision bias, researchers start to consider objectives other than risk neutral objectives. Instead, they consider the risk-averse objectives and even the lossaverse objectives from prospect theory. According to the loss averse theory, people are more averse to losses than they are attracted to the same-sized gains.

In this paper, we study a periodic review inventory control and borrowing decisions for a loss-averse retailer in a finite horizon. Unsatisfied demand is lost. We find that the optimal inventory control policy is a capital-dependent base-stock policy. Moreover, we demonstrate with numerical examples that the optimal order-up-to level is nondecreasing with respect to the accumulated wealth and the loss aversion indicator. The higher the loss aversion indicator/the accumulated wealth is, the lower the base-stock level is. The theoretical results can be applied to the fashion and textiles industry. Although we have characterized the optimal inventory control policy for the financial constrained retailer in a finite horizon, we still can extend our current study in several directions. First, with financial constraint, operations management tools like inventory control and will not be enough to match supply with demand. Marketing instruments like pricing and sales effort should be incorporated in such situation. Second, we assume that the target level $\alpha$ is exogenously determined in this model. An interesting extension is to set $\alpha$ to be the initial cash flow level. Then, how much initial cash flow should the loss-averse retailer invest at the beginning of the planning horizon? In the future we will take these issues into consideration.

\section{Acknowledgments}

The authors would like to thank the editor and two anonymous referees, whose comments improve their work significantly. L. Ma was partially supported by the National Natural Science Foundation of China (NSFC) with Grant nos. 71001073 and 71271182 and the Natural Science Foundation of SZU (201121). W. Xue was partially supported by NSFC with
Grant nos. 71171105 and 70932003, the China Postdoctoral Science Foundation with Grant no. 2012M521054, and the Cultivation Fund of the Key Scientific and Technical Innovation Project, Ministry of Education of China with Grant no. 708044. Y. Zhao was partially supported by the NSFC with Grant no. 71101028, the Program for Innovative Research Team in UIBE, and the Program for Excellent Talents, UIBE. $\mathrm{X}$. Lin was partially supported by the NSFC with Grant no. 70601016.

\section{References}

[1] M. Ayyagari, A. Demirguc-kunt, and V. Maksimovic, "Firm innovation in emerging markets: the role of finance, governance, and competition," Journal of Financial and Quantitative Analysis, vol. 46, no. 6, pp. 1545-1580, 2006.

[2] B. Kogut and N. Kulatilaka, "Operating exibility, global manufacturing and the option value of a multinational network," Management Science, vol. 40, no. 1, pp. 123-139, 1994.

[3] A. Huchzermeier and M. A. Cohen, "Valuing operational flexibility under exchange rate risk," Operations Research, vol. 44, no. 1, pp. 100-113, 1996.

[4] J. R. Birge, "Option methods for incorporating risk into linear capacity planning models," Manufacturing and Service Operations Management, vol. 2, no. 1, pp. 19-31, 2000.

[5] G. Hadley and T. Whitin, Analysis of Inventory Systems, Prentice-Hall Press, 1963.

[6] M. J. Rosenblatt, "Multi-item inventory system with budgetary constraint: a comparison between the lagrangian and the fixed cycle approach," International Journal of Production Research, vol. 19, no. 4, pp. 331-339, 1981.

[7] M. J. Rosenblatt and U. G. Rothblum, "On the single resource capacity problem for multi-item inventory systems," Operations Research, vol. 38, no. 4, pp. 686-693, 1990.

[8] X. Chao, J. Chen, and S. Wang, "Dynamic inventory management with cash flow constraints," Naval Research Logistics, vol. 55, no. 8, pp. 758-768, 2008.

[9] J. Kahn, "Why is production more volatile than sales? Theory and evidence on the stockoutavoidance motive for inventory holding," Quarterly Journal of Economics, vol. 107, pp. 481-510, 1992.

[10] C. X. Wang and S. Webster, "The loss-averse newsvendor problem," Omega, vol. 37, no. 1, pp. 93-105, 2009.

[11] C. Camerer, L. Babcock, G. Loewenstein, and R. Thaler, "Labor supply of New York city cabdrivers: one day at a time," Quarterly Journal of Economics, vol. 112, no. 2, pp. 406-441, 1997.

[12] M. E. Schweitzer and G. P. Cachon, "Decision bias in the newsvendor problem with a known demand distribution: experimental evidence," Management Science, vol. 46, no. 3, pp. 404420, 2000.

[13] H. S. Lau, "The newsboy problem under alternative optimization objectives," Operational Research Society Journal, vol. 31, no. 6, pp. 525-535, 1980.

[14] L. Eeckhoudt, C. Gollier, and H. Schlesinger, "The risk-averse (and prudent) newsboy," Management Science, vol. 41, pp. 786794, 1995.

[15] F. Chen and A. Federgruen, "Mean-variance analysis of basic inventory models;" Working Paper, Graduate School of Business, Columbia University, New York, NY, USA, 2001. 
[16] T.-M. Choi, D. Li, and H. Yan, "Mean-variance analysis of a single supplier and retailer supply chain under a returns policy," European Journal of Operational Research, vol. 184, no. 1, pp. 356-376, 2008.

[17] T. M. Choi, D. Li, H. Yan, and C. H. Chiu, "Channel coordination in supply chains with agents having mean-variance objectives," Omega, vol. 36, no. 4, pp. 565-576, 2008.

[18] A. Hafezalkotob, A. Makui, and S. Sadjadi, "Strategic and tactical design of competing decentralized supply chain networks with risk-averse participants for markets with uncertain demand," Mathematical Problems in Engineering, vol. 2011, Article ID 325610, 27 pages, 2011.

[19] L. Ma, F. Liu, S. Li, and H. Yan, "Channel bargaining with riskaverse retailer," International Journal of Production Economics, vol. 139, no. 1, pp. 155-167, 2012.

[20] X. Chen, M. Sim, D. Simchi-Levi, and P. Sun, "Risk aversion in inventory management," Operations Research, vol. 55, no. 5, pp. 828-842, 2007.

[21] J. Buzacott, H. Yan, and H. Zhang, "Risk analysis of commitment-option contracts with forecast updates," IIE Transactions, vol. 43, no. 6, pp. 415-431, 2011.

[22] T.-M. Choi and C.-H. Chiu, Risk Analysis in Stochastic Supply Chains: A Mean-Risk Approach, Springer Press, 2012.

[23] L. Ma, "Loss-averse newsvendor problem with general profit target," International Journal of Information and Decision Sciences, vol. 1, pp. 145-163, 2008.

[24] C. X. Wang, “The loss-averse newsvendor game," International Journal of Production Economics, vol. 124, no. 2, pp. 448-452, 2010.

[25] H. Shen, Z. Pang, and T. C. E. Cheng, "The component procurement problem for the loss-averse manufacturer with spot purchase," International Journal of Production Economics, vol. 132, no. 1, pp. 146-153, 2011.

[26] L. Ma, Y. Zhao, W. Xue, H. Yan, and T. Cheng, "Loss-averse newsvendor model with two ordering opportunities and market information updating," International Journal of Production Economics, vol. 140, no. 2, pp. 912-921, 2012.

[27] F. Modigliani and M. Miller, "The cost of capital, corporation finance and the theory of investment," The American Economic Review, vol. 48, no. 3, pp. 261-297, 1958.

[28] M. Harris and A. Raviv, "The theory of capital structure," The Journal of Finance, vol. 46, no. 1, pp. 297-355, 1991.

[29] D. Gupta and Y. Gerchak, "Quantifying operational synergies in a merger/acquisition," Management Science, vol. 48, no. 4, pp. 517-533, 2002.

[30] J. Zhou and A. H. Groenevelt, "Impacts of financial collaboration in a three-party supply chain," Working Paper, Caroll School of Management, Boston College, Boston, Mass, USA, 2008.

[31] M. Dada and Q. Hu, "Financing newsvendor inventory," Operations Research Letters, vol. 36, no. 5, pp. 569-573, 2008.

[32] G. Lai, L. G. Debo, and K. Sycara, "Sharing inventory risk in supply chain: the implication of financial constraint," Omega, vol. 37, no. 4, pp. 811-825, 2009.

[33] S. Yang and J. Birge, "How inventory is (should be) financed: trade credit in supply chains with demand uncertainty and costs of financial distress," Working Paper, London Business School, London, UK, 2010.

[34] P. Kouvelis and W. Zhao, "The newsvendor problem and priceonly contract when bankruptcy costs exist," Production and Operations Management, vol. 20, no. 6, pp. 921-936, 2011.
[35] B. Jing, X. Chen, and G. Cai, "Equilibrium financing in a distribution channel with capital constraint," Production and Operations Management, vol. 21, no. 6, pp. 1090-1101, 2012.

[36] T. W. Archibald, L. C. Thomas, J. M. Betts, and R. B. Johnston, "Should start-up companies be cautious? Inventory policies which maximise survival probabilities," Management Science, vol. 48, no. 9, pp. 1161-1174, 2002.

[37] V. Babich and M. J. Sobel, "Pre-IPO operational and financial decisions," Management Science, vol. 50, no. 7, pp. 935-948, 2004.

[38] J. A. Buzacott and R. Q. Zhang, "Inventory management with asset-based financing," Management Science, vol. 50, no. 9, pp. 1274-1292, 2004.

[39] Q. Hu and M. C. Sobel, "apital structure and inventory management," Working Paper, Weatherhead School of Business, Case Western Reserve University, Cleveland, Ohio, USA, 2008.

[40] Q. Hu, M. Sobel, and D. Turcic, "Optimization of inventory and dividends with risky debt," Working Paper, Weatherhead School of Business, Case Western Reserve University, Cleveland, Ohio, USA, 2010.

[41] J. Song and J. Tong, "Payment schemes, financing costs, and inventory management," Working Paper, Fuqua School of Business, Duke University, Durham, NC, USA, 2011.

[42] W. Luo and K. Shang, "Integrating inventory replenishment and cash payment decisions in supply chains," Working Paper, Fuqua School of Business, Duke University, Durham, NC, USA, 2012.

[43] M. Bouakiz and M. J. Sobel, "Inventory control with an exponential utility criterion," Operations Research, vol. 40, no. 3, pp. 603-608, 1992.

[44] D. Kahneman and A. Tversky, "Prospect theory: an analysis of decision under risk," Econometrica, vol. 47, no. 2, pp. 263-239, 1979.

[45] D. Heyman and M. Sobel, Stochastic Models in Operations Research: Stochastic Optimization, McGraw-Hill Companies, 1984.

[46] M. Campello, J. Graham, and R. Campbell, "The real effects of financial constraints: evidence from a financial crisis," Working Paper, National Bureau of Economic Research, Cambridge, Mass, USA, 2009. 


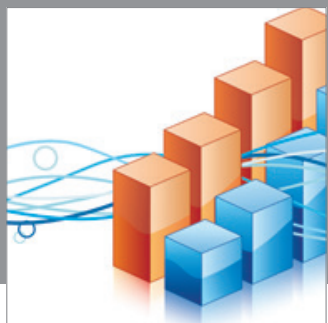

Advances in

Operations Research

mansans

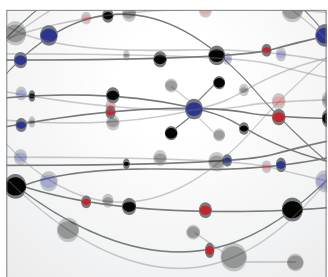

The Scientific World Journal
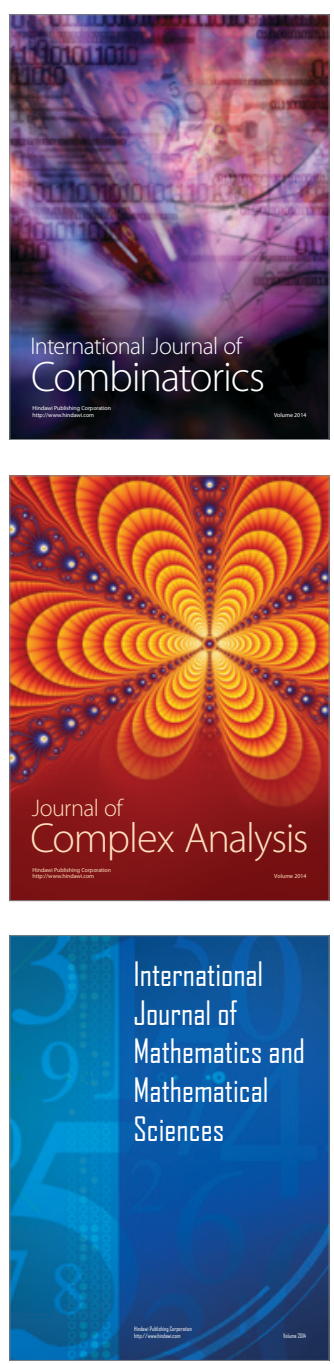
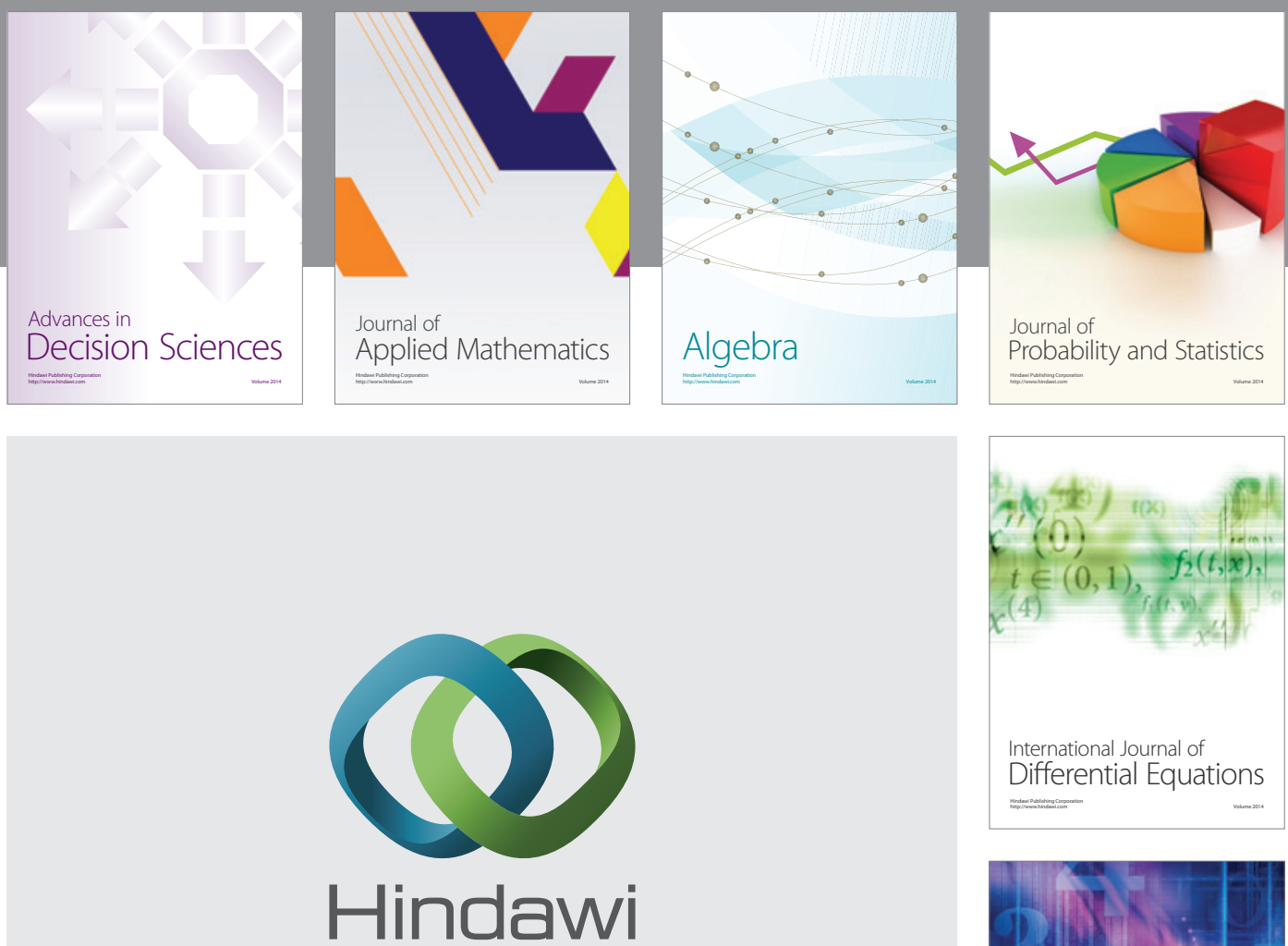

Submit your manuscripts at http://www.hindawi.com
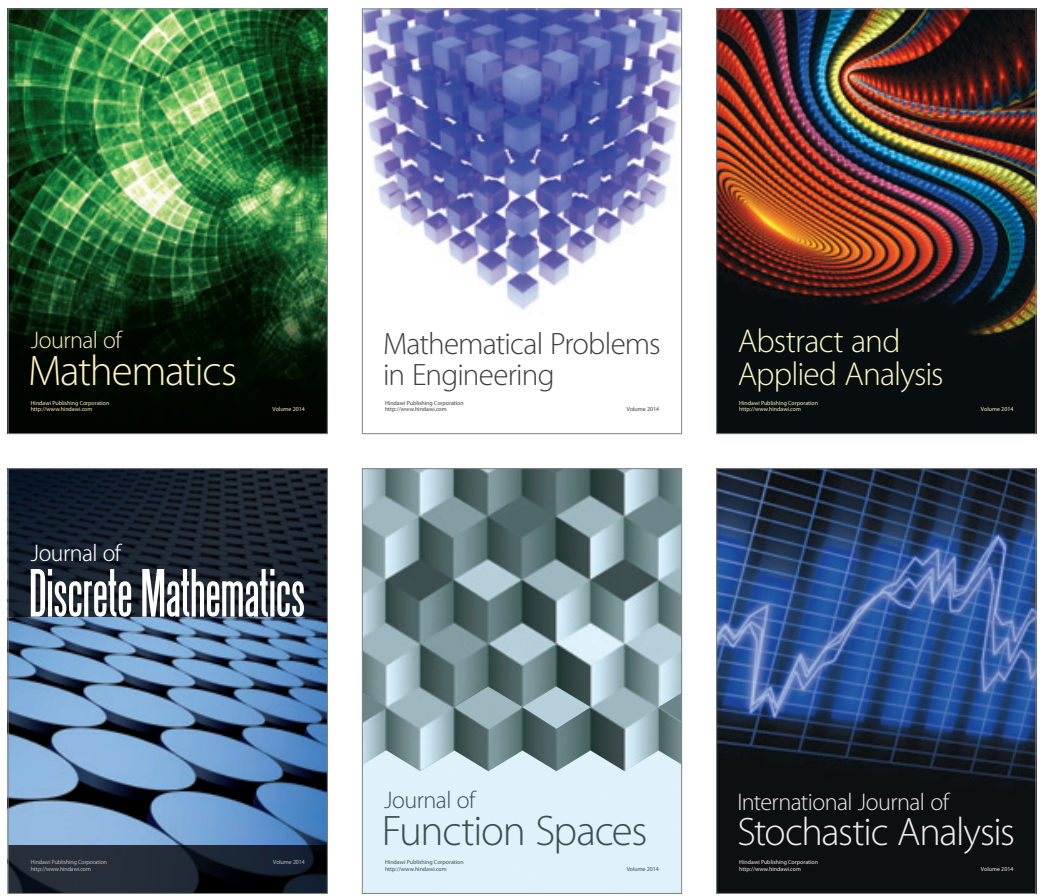

Journal of

Function Spaces

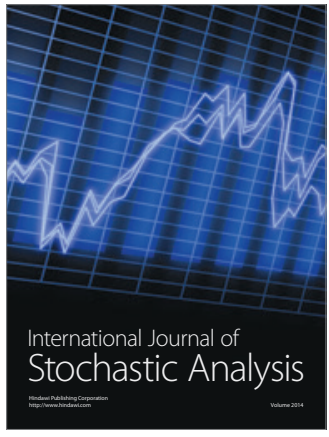

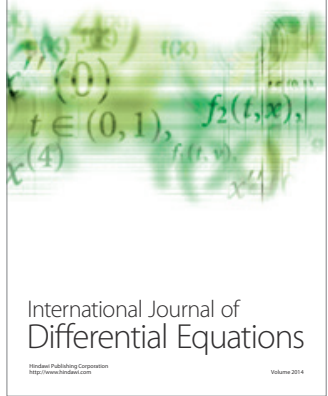
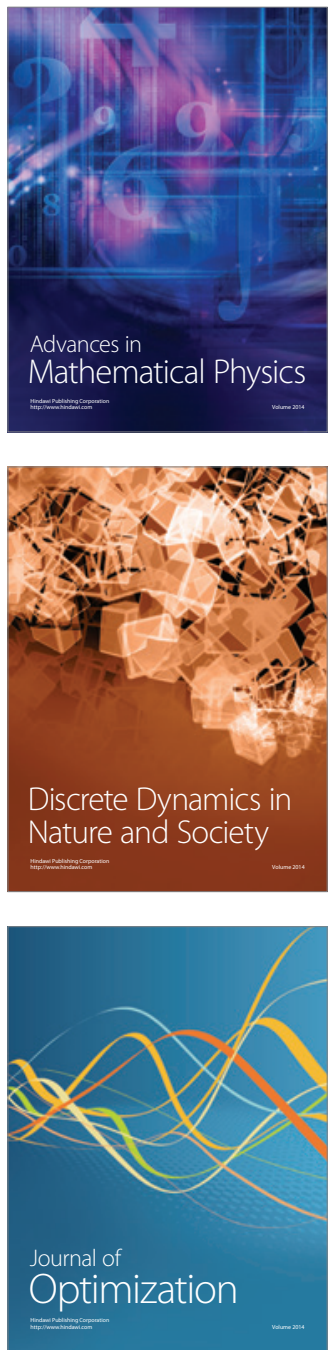